\title{
Esophageal high pressure zones: Effect of periesophageal structures on esophageal manometric recording
}

\author{
G BÉDARD PA, A PELLICANO MD, R STE-MARIE MD
}

G BÉdARD, A PELliCANO, R STE-MARIE. Esophageal high pressure zones: Effect of periesophageal structures on esophageal manometric recording. Can J Gastroenterol 1994;8(4):239-245. During the course of esophageal motility studies, short zones of elevated esophageal baseline pressure are occasionally noticed. The aim of this study is to determine their frequency and their cause. Among 77 consecutive esophageal manometries (group 1), 17 cases (22\%) of 'esophageal high pressure zones' (EHPZs) were recorded. Thirty-three additional patients (group 2) were evaluated and 18 other cases of EHPZ were found; in the latter group, a miniature sound microphone was positioned on a carotid artery. When a high pressure zone was identified, the manometric catheter was immobilized; the patient underwent a chest $\mathrm{x}$-ray, with the radiopaque marker imbedded in the catheter used to locate the thoracic structures adjacent to EHPZs. In both groups, indentations (pressure spikes) over the high pressure zones occurred synchronously with the patients' radial or carotid pulse. Results suggest that EHPZs are caused by the compression and pulsations of vascular or cardiac periesophageal structures; the aortic arch is responsible for the manometric EHPZ when it is found between 10 and $14 \mathrm{~cm}$ above the lower esophageal sphincter whereas the left auricle is the cause of the EHPZ if it is located between 4 and $7 \mathrm{~cm}$ above the lower esophageal sphincter.

Key Words: Esophageal high pressure zone, Esophageal manometry, Esophagus, Heart, Mediastinal vascular trunks

Segments œsophagiens hypertensifs; effet des structures périœesophagiennes sur l'enregistrement de la manométrie œesophagienne

RÉSUMÉ : Au cours d'études de la motilité oesophagienne, nous remarquons occasionnellement l'élévation de la pression de base sur de courts segments du corps œesophagien. Cette étude a eu pour but de déterminer leur fréquence et leur cause. Parmi 77 tracés consécutifs de manométrie cesophagienne (groupe 1), nous

continued on next page

Gastrointestinal Motility Laboratory, Division of Gastroenterology, Departments of Medicine and Radiology, Hôtel-Dieu de Sherbrooke, Sherbrooke, Quebec

Correspondence: Dr A Pellicano, Hôpital du Sacré-Coeur de Montréal, Centre hospitalier universitaire, Université de Montréal, 5400 ouest, boul Gouin, Montréal, Québec H4J 1C5. Telephone (514) 338-3652

Received for publication October 28, 1993. Accepted February 10, 1994
M ANOMETRIC STUDIES OF THE esophagus have become indispensable in evaluating esophageal motility. Many studies have been published to help in the analysis and interpretation of manometric recordings.

Dalton (1) recently reported esophageal high pressure zones (EHPZs) surmounted by repetitive pressure spikes in different parts of the esophageal body, and suggested that these indentations might be caused by the heart or by an electric interference. Berenzweig et al (2) and Mittal et al (3) described this phenomenon in rare cases of dysphagia lusoria and aortica. The latter group showed that it could be found in normal volunteers. Cappell (4) recently demonstrated a mid-EHPZ with superimposed cyclic pressure waves produced by left atrial dilation. The aim of this study was to look for and study these EHPZs systematically, determine their frequency and attempt to identify the mediastinal structures causing them; the following is a presentation of our findings.

\section{PATIENTS AND METHODS}

Seventy-seven consecutive patients (group 1) who presented to the HottelDieu de Sherbrooke motility laboratory were prospectively evaluated from March to September 1990. During this period 17 patients presented a high pressure zone in the region of the 
avons relevé 17 cas $(22 \%)$ de «segments cesphagiens hypertensifs» (SOH). Trente-trois patients additionnels (groupe 2) furent évalués et 18 autres cas de $\mathrm{SOH}$ furent retrouvés; dans ce dernier groupe, un microphone miniatue fut positionné sur une carotide. Lorsqu'un segment hypertensif était identifié, le cathéter manométrique était immobilisé; le patient subissait une radiographie pulmonaire et le cathéter muni de marqueurs radioopaques servait à identifier les structures thoraciques adjacentes au SOH. Dans les deux groupes, des indentations (pointes de pression) au sommet des $\mathrm{SOH}$ apparaissaient de façon synchrone avec le pouls radial ou carotidien des malades. En conclusion, notre étude suggère que les $\mathrm{SOH}$ résultent de la compression et des pulsations provenant des structures péri-cesophagiennes vasculaires ou cardiaques; la crosse aortique est responsable du SOH lorsque ce dernier est retrouvé entre 10 et $14 \mathrm{~cm}$ au-dessus du sphincter œesophagien inférieur alors que l'oreillette gauche l'est lorsque le SOH est localisé entre 4 et $7 \mathrm{~cm}$ au-dessus de sphincter œesophagien inférieur.

\section{TABLE 1}

Clinical characteristics of group 1 patients

\begin{tabular}{|c|c|c|c|}
\hline $\begin{array}{l}\text { Patient number/ } \\
\text { age (years)/sex }\end{array}$ & Reason for motility studies & Endoscopy & Barium meal \\
\hline $1 / 29 /$ Female & $\mathrm{CP}$ & 0 & 1 \\
\hline 2/44/Male & CP, GER & 2 & 0 \\
\hline $3 / 27 /$ Female & GER & 1,2 & ND \\
\hline 4/44/Male & GER & $1,2,4$ & 0 \\
\hline 5/61/Female & GER & 1,2 & 0 \\
\hline $6 / 44 /$ Female & CP, GER & 0 & 9 \\
\hline 7/51/Female & GER, PN & 0 & ND \\
\hline $8 / 28 /$ Male & GER & 2,8 & 9 \\
\hline 9/27/Male & $A C, H M(a), P N$ & ND & ND \\
\hline 10/58/Female & GER & 1,2 & ND \\
\hline $11 / 61 /$ Female & D, GERD & 0 & 7 \\
\hline 12/49/Male & D & 1 & 1.6 \\
\hline 13/29/Male & GER & $1,2,8$ & 0 \\
\hline 14/51/Female & GER & $1,2,5$ & ND \\
\hline 15/43/Female & CP, GER & 0 & ND \\
\hline 16/66/Male & GER & 2 & ND \\
\hline 17/57/Male & GER & 1,5 & ND \\
\hline
\end{tabular}

o Normal; 1 Hiatal hernia; 2 Gastroesophageal junction incompetency; 3 Esophageal erythema: 4 Esophageal erosions; 5 Esophageal ulceration; 6 Esophageal stenosis; 7 Esophageal hypomotility; 8 Whitish thickened mucosa: 9 Gastroesophageal reflux (GER): AC Achalasia; CP Chest pain: D Dysphagia: PN Post-Nissen: HM(a) Heller's myotomy postoperative control

esophageal body. The age of these eight men and nine women ranged from 27 to 66 years (mean 38.5 ). The reason for their evaluation was gastroesophageal reflux in nine cases, dysphagia in one case and chest pain in another; in six cases there was more than one reason. Patients underwent an esophageal motility study followed by a chest x-ray if an EHPZ was found; when clinically indicated, a Bernstein test and $24 \mathrm{~h}$ ambulatory esophageal $\mathrm{pH}$ monitoring were performed. All but one patient underwent a gastroscopy - the patient with achalasia underwent it prior to surgery (Table 1). All patients signed an informed consent form. An EHPZ was arbitrarily defined as a pressure plateau rising at least $10 \mathrm{mmHg}$ above the adjacent esophageal segments.

The esophageal motility studies were carried out following a standard procedure. A polyvinyl catheter composed of six capillary tubes with side holes (inner diameter $0.8 \mathrm{~mm}$ to outer diameter $4.8 \mathrm{~mm}$, ESM 6R, Arndorfer Inc, Wisconsin) was used for all the studies: the three distal side holes are located at the same level and are oriented radially at $120^{\circ}$ angles, whereas the three proximal side holes, while still oriented radially, are set $5 \mathrm{~cm}$

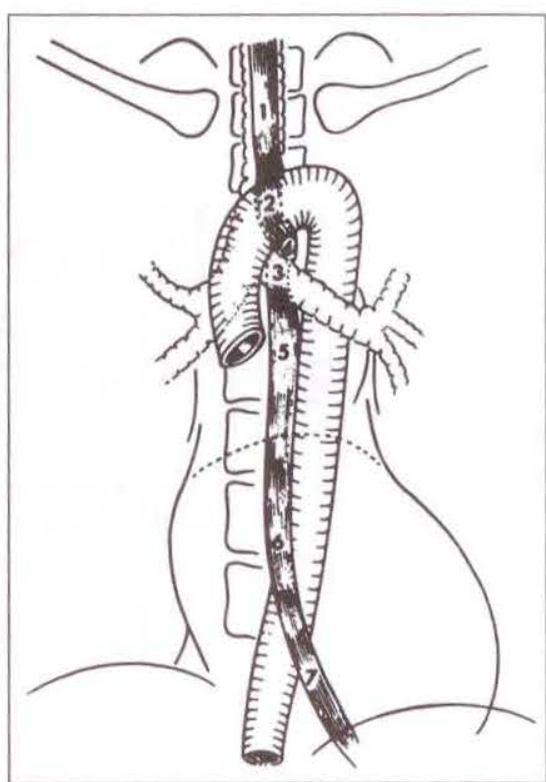

Figure 1A) Segments or the esophagus: posteroanterior view. 1 Paratracheal; 2 Aortic; 3 Bronchial; 4 Interaorticobronchial triangle; 5 Interbronchial; 6 Retrocardial; 7 Epiphrenic

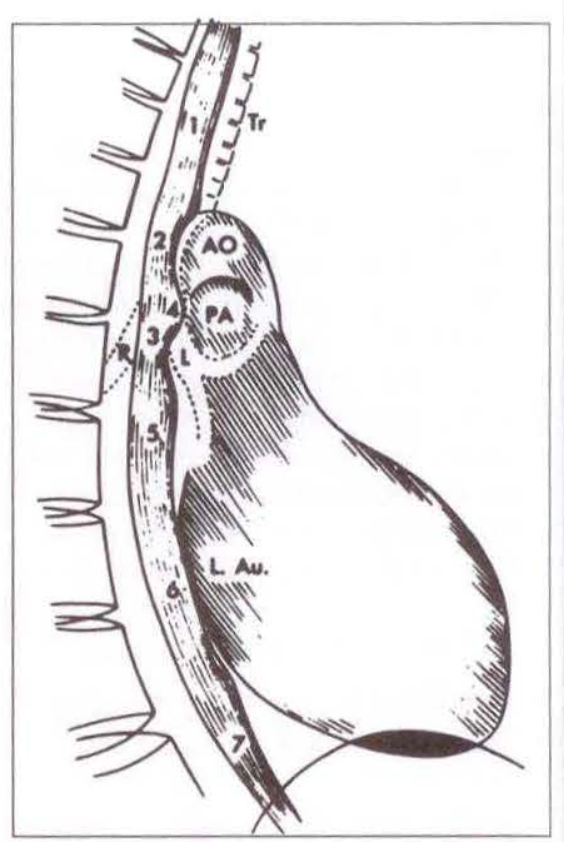

Figure 1B) Segments of the esophagus: right anterior oblique view. I Paratracheal; 2 Aortic; 3 Bronchial; 4 Interaorticobronchial; 5 Interbronchial; 6 Retrocardial; 7 Epiphrenic; AO Aorta; L Left main bronchi; L Au Left auricle; PA Pulmonary artery; R Right main bronchi; Tr Trachea. Reproduced with permission from reference 5

apart. The catheter is equipped with radiopaque markers located immedi. ately below each side hole. Each capillary was continuously perfused with distilled water at the rate of $0.6 \mathrm{~mL} / \mathrm{min}$ 
using a pneumohydraulic capillaryinfusion pump powered by compressed nitrogen (Arndorfer Inc). The catheter was connected to external pressure transducers (Beckman model 4-327 C, Georgia) that, in turn, were connected to a SensorMedics model R-611 dynograph (SensorMedics Corps, California). This system has a pressure rise rate greater than $300 \mathrm{mmHg} / \mathrm{s}$. In group 1, a miniature sound microphone (SensorMedics) taped to the patient's neck recorded swallows; in group 2, the microphone was located on a carotid artery to record arterial pulsations and the patient's swallows simultaneously. Patients fasted for $5 \mathrm{~h}$ before evaluation. The catheter was introduced transnasally, all patients lying supine. Patients were given $5 \mathrm{~mL}$ of room-temperature tap water to swallow. Lower esophageal sphincter (LES) pressures were recorded with the three distal side holes by the station and rapid pullthrough techniques. The catheter was positioned in the esophageal body, the side holes being located 3,8 and $13 \mathrm{~cm}$ above the LES. The amplitude, duration and velocity of the esophageal contraction waves were evaluated following 10 swallows, each spaced by about 20 to $25 \mathrm{~s}$. The motility study was continued, pulling back the catheter in $1 \mathrm{~cm}$ increments. This technique allowed all EHPZs to be revealed.

Each high pressure zone was evaluated using the three distal side holes of the manometric catheter. The ports' radial orientation $\left(120^{\circ}\right.$ angles) showed that the EHPZs have an asymmetric pressure profile; one of the three plateaus was always more elevated as recorded by one of the three distal side holes. When the catheter was pulled back, pressure spikes appeared over the high pressure zones. The dynograph's frequency response was increased to sharpen the definition of the pressure spikes. At the conclusion of the manometric study, the catheter was pushed down to position the three distal side holes over the EHPZ for further evaluation. Thereafter the patient underwent a posteroanterior and lateral chest $x$-ray to localize the catheter's radiopaque markers and thus facilitate identification of the mediastinal struc-

TABLE 2

\section{Clinical characteristics of group 2 patients}

\begin{tabular}{lccc}
\hline $\begin{array}{l}\text { Patient number/ } \\
\text { age (years)/sex }\end{array}$ & $\begin{array}{c}\text { Reason for motility } \\
\text { słudies }\end{array}$ & Endoscopy & Barium meal \\
\hline 18/38/Female & GER & $1,2,5$ & ND \\
19/32/Female & CP & 0 & 0 \\
20/61/Male & CP, D, GER & 0 & 1 \\
21/38/Female & CP, GER & 0 & ND \\
22/63/Female & D & G, B & ND \\
\hline
\end{tabular}

o Normal; 1 Hiatal hernia; 2 Gastroesophageal junction incompetency; 5 Esophageal ulceration: B Bulbitis; CP Chest pain; D Dysphagia; G Gastritis; GER Gastroesophageal reflux; ND Not done

tures facing the catheters distal side holes. The $\mathrm{x}$-rays were read blindly by a radiologist and the mediastinal structures were identified according to the esophageal segments described by Brombart (5) (Figure 1).

Each EHPZ was evaluated by determining its position ( $\mathrm{cm}$ above the LES), its length $(\mathrm{cm})$ and its 'plateau pressure' $(\mathrm{mmHg})$. The EHPZ plateau pressure was established by asking the patient to stop breathing in midexpiration for 5 to $10 \mathrm{~s}$. A horizontal line was drawn on the manometric tracing at the centre of the pressure spikes' vertical excursions; although the line could have been drawn at the base of the pressure spikes, we felt that placing it midway through the spikes' vertical excursion represented the 'mean' intraesophageal pressure. The plateau pressure value was obtained by subtracting the mean intrathoracic baseline pressure from the value obtained at the horizontal line. In group 1 , when clinically indicated, a Bernstein test and $24 \mathrm{~h}$ ambulatory esophageal $\mathrm{pH}$ monitoring were performed.

As the determination of the correlation of the pressure spikes with the radial pulse appeared subjective, the miniature sound microphone was moved over a carotid artery. In most patients, swallowing could simultaneously be recorded with the arterial pulsations; it thus became easier to correlate these arterial pulsations precisely with the pressure spikes surmounting the EHPZs on the same tracing. Thirty-three additional patients (group 2) were evaluated from May to June 1992 inclusively; 18 patients with EHPZs were identified and were studied using the same protocol as
TABLE 3

Esophageal motility studies: group 1

Patient

number Manometric findings

$1 \quad$ RLESP: 6.6 (SPT), 4.2 (RPT):

Esophageal body: MWD $6.0 \mathrm{~s}$

2

Normal

3 Normal

$4 \quad$ Esophageal body: MWD $5.5 \mathrm{~s}$

$5 \quad$ Normal

6 Normal

$7 \quad$ Normal

8 Normal

9 Achalasia

10 Esophageal body: MWD $6.4 \mathrm{~s}$

11 Normal

12 Esophageal body: MWD $6.5 \mathrm{~s}$

13 Normal

14 Normal

15 Normal

16 Normal

17 RLESP: 8.3 (SPT), 4.4 (RPT):

Esophageal body: MWD $6.7 \mathrm{~s}$

Resting lower esophageal sphincter pressure (RLESP): station pull-through $(S P D)=12 \pm 5 \mathrm{mmHg}$ : rapid pull-through (RPI) $=15 \pm 9 \mathrm{mmHg}$ (normal values from 13 controls). MWD Mean wave duration $3 \mathrm{~cm}$ above lower esophageal sphincter in seconds

for patients in group 1. Carotid pulsations could be recorded in only five patients; adiposity interfered with a clear recording in the others. Of the five evaluable patients in group 2, there were four women and one man; their age ranged from 32 to 63 years (mean 46.4) (Table 2).

\section{RESULTS}

Group 1: Seventy-seven esophageal motility studies were performed in group $1 ; 17$ cases $(22 \%)$ presented with at least one EHPZ. A chest $\mathrm{x}$-ray could not be obtained in three of these cases. 


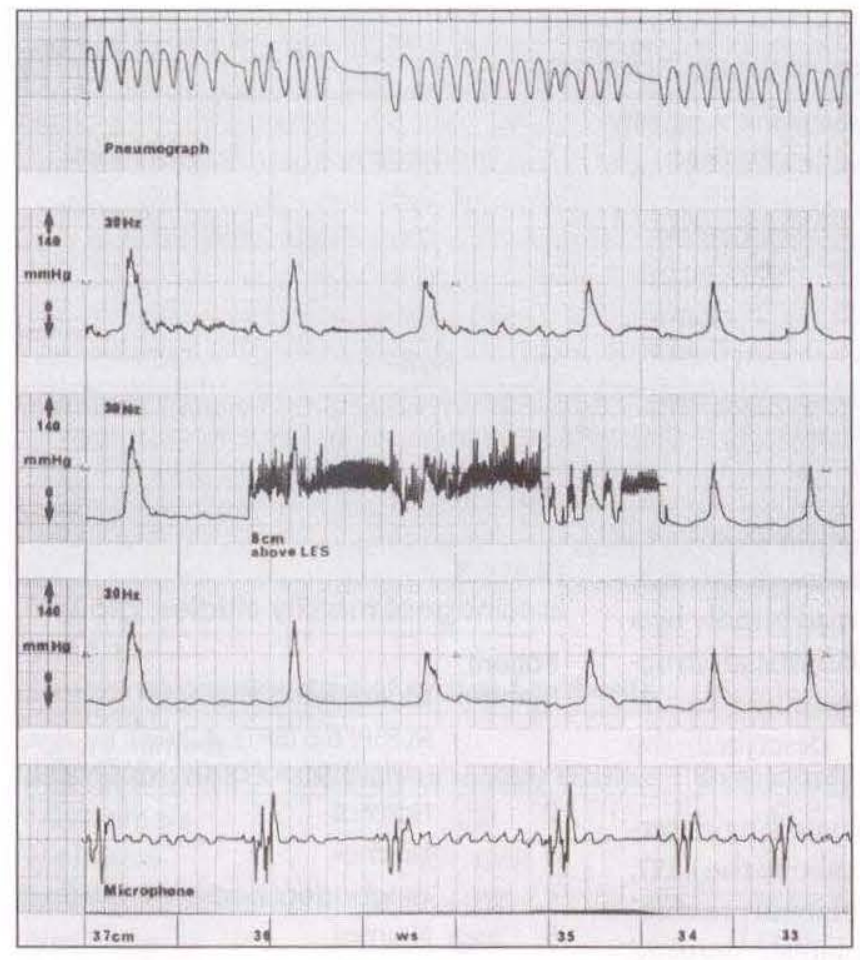

Figure 2) Single esophageal high pressure zone. Manometry tracing from patient 11 recorded with the distal side holes of the manometric catheter; the side holes are located at the same level. The neck microphone indicates swallowing of $5 \mathrm{~mL}$ water; the high pressure zone is located at the level of the retrocardial segment, $8 \mathrm{~cm}$ above the lower esophageal sphincter (LES), and is recorded from 36 to $34 \mathrm{~cm}$ from the nares. Notice at the top of the tracing that the patient stops breathing in midexpiration. A line is drawn the middle of the stylet's excursion. The pressure of the high pressure zone plateau is obtained by subtracting the value at the adjacent intrathoracic baseline pressure

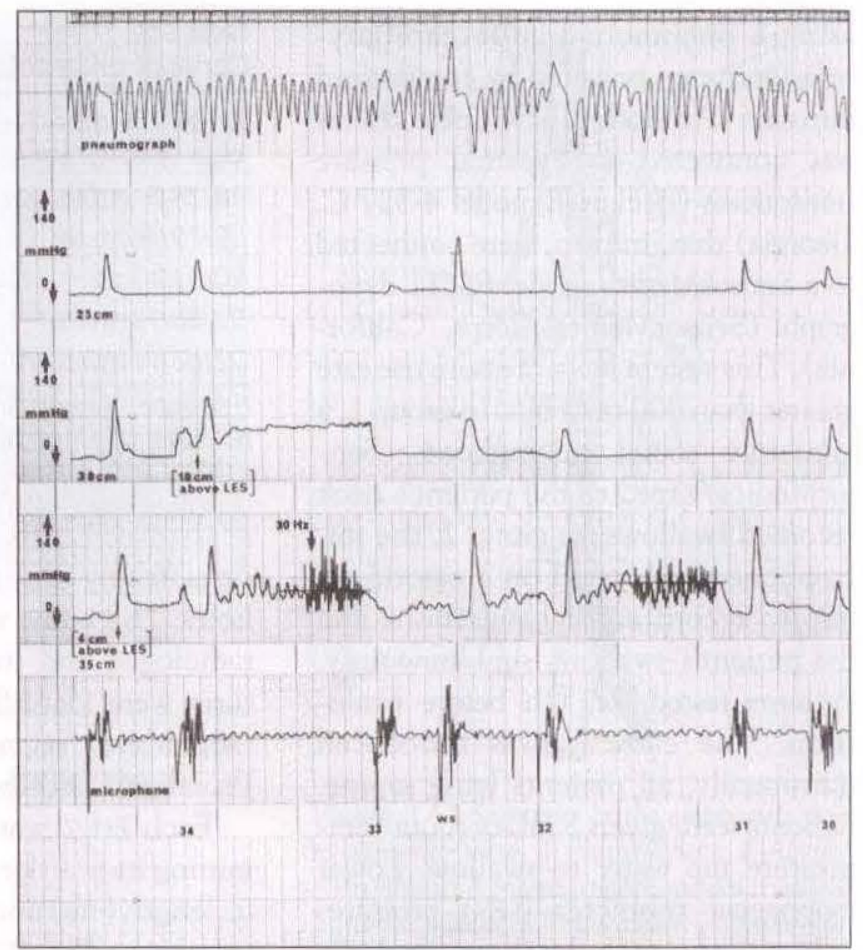

Figure 3) Two adjacent esophageal high pressure zones. Manometry tracing from patient 3 . The first high pressure zone is located between 29 and $28 \mathrm{~cm}$ (aortic segment) and the second between 35 and $31 \mathrm{~cm}$ from the nares (retrocardial segment). Notice a fall of the plateau pressure when the esophageal contraction crosses the high pressure zone. The esophageal high pressure zone appears to behave as a sphincter. LES Lower esophageal sphincter
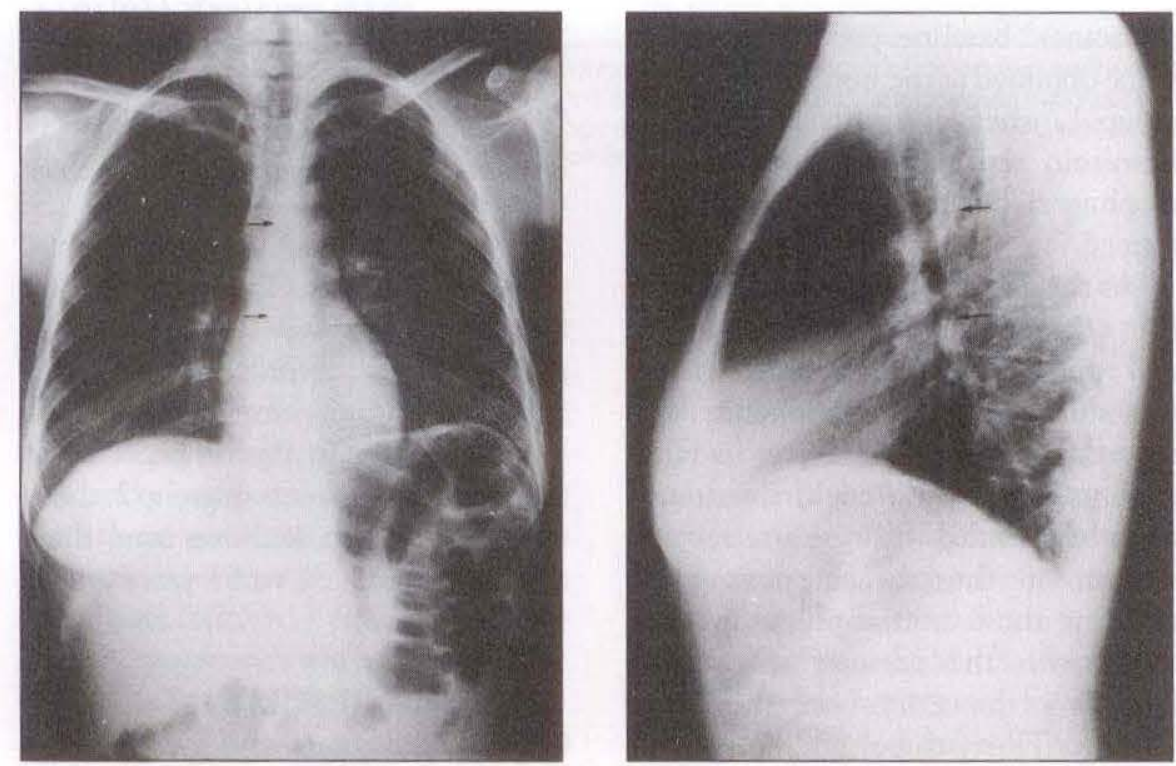

Figure 4) Chest $x$-rays of patient 3. A (left) Posteroanterior view; B (right) Lateral view. Arrows show radiopaque markers in the manometry catheter; lower arrow indicates the marker adjacent to the high pressure zone and the retrocardial segment of the esophagus; upper arrow is adjacent to the aortic segment of the esophagus
The results of the manometric findings are presented in Table 3.

Most of these patients presented with only one EHPZ (Figure 2); interestingly, two distinct and simultaneous zones were found in four cases $(23.5 \%)$ (Figures 3,4).

The length of the EHPZ varied from 1.0 to $5.0 \mathrm{~cm}$ (average $2.7 \mathrm{~cm}$ for the 17 cases). When the patient was asked to stop breathing in midexpiration, a pressure plateau formed above the intrathoracic baseline and measured from 14 to $134 \mathrm{mmHg}$ (mean 48.1). This high pressure zone could be found any time the catheter was moved back to where it was first observed. EHPZs were most often located at the level of the aortic segment (eight cases) and of the retrocardial segment (six cases) of the esophagus; the esophageal segment with the highest mean plateau pressure 
$(74.25 \mathrm{mmHg})$ was the aortic segment (Table 4).

Repetitive pressure spikes rose above every pressure plateau and occurred synchronously with the radial pulse (Figures 2,3). Following a wet swallow, the esophageal contraction wave crossed through the high pressure zone; preceding the arrival of the contraction wave, a transient relaxation of the EHPZ pressure plateau was observed.

Chest $\mathrm{x}$-rays were read blindly by one author; no significant pathology pulmonary, mediastinal or cardiac was found. The $\mathrm{x}$-rays showed that the hypertensive zones, indicated by radiopaque markers, were contiguous to the mediastinal structures described in Table 4.

Group 2: In group 2 patients, the sound microphone was positioned on the carotid artery to demonstrate even further the simultaneity between the pressure spikes above the EHPZs and the vascular (carotid) pulsations (Figure 5). The motility studies of these patients are reported in Table 5. Their EHPZ characteristics are summarized in Table 6 . The frequency of mediastinal structures found beside the EHPZs reported in these patients varied from that reported for group 1; this may have been related to the difficulty in picking up a carotid pulsation with the sound microphone in obese patients. A simultaneous electrocardiogram (ECG) would probably have demonstrated this simultaneity even better.

When values from patients in both groups are combined, mean length of EHPZs is $2.6 \mathrm{~cm}$ and mean pressure of EHPZs is $52.8 \mathrm{mmHg}$. When the high pressure zone is found between 10 and $14 \mathrm{~cm}$ above the LES it can be assumed that it is adjacent to the aortic arch; when it is located between 4 and $7 \mathrm{~cm}$ above the LES, it should be beside the left auricle.

Symptoms, endoscopic findings, barium meal results, overall manometric findings, Bernstein tests and $24 \mathrm{~h}$ ambulatory $\mathrm{pH}$ monitoring results could not be related to a specific esophageal condition (Tables 1,2,3, 5). Furthermore, barium meals did not show any mediastinal structure abnormally compressing the esophagus.
TABLE 4

Esophageal high pressure zone: group 1

\begin{tabular}{lcccc}
\hline $\begin{array}{l}\text { Patient } \\
\text { number }\end{array}$ & $\begin{array}{c}\text { Structure(s) surrounding } \\
\text { marker }\end{array}$ & $\begin{array}{c}\text { EHPZ: } \\
\text { cm above LES }\end{array}$ & $\begin{array}{c}\text { EHPZ } \\
\text { length }(\mathrm{cm})\end{array}$ & $\begin{array}{c}\text { EHPZ pressure } \\
(\mathrm{mmHg})\end{array}$ \\
\hline 1 & AS & 13 & 1 & 86 \\
2 & AS & 10 & 1 & 70 \\
3 & AS and RS & 9 and 4 & 1 and 5 & 45 and 40 \\
4 & AS & 12 & 1 & 128 \\
5 & AS and RS & 11 and 4 & 1 and 3 & 20 and 28 \\
6 & RS & 5 & 2 & 32 \\
7 & RS & 6 & 4 & 32 \\
8 & AS & 12 & 4 & 56 \\
9 & AS & 11 & 1 & 52 \\
10 & AS & 13 & 2 & 134 \\
11 & BS & 8 & 5 & 48 \\
12 & BS & 8 & 1 & 54 \\
13 & IBS and RS & 11 and 4 & 1 and 3 & 31 and 14 \\
14 & X-R ND & 5 & 5 & 34 \\
15 & BS and RS & 10 and 5 & 3 and 3 & 32 and 40 \\
16 & X-R ND & 4 & 3 & 28 \\
17 & X-R ND & 13 & 2 & 48 \\
\hline
\end{tabular}

- Manometric catheter distal radiopaque marker. I Interbronchial segment (esophageal high pressure zone (EHPZ) mean pressure $40.0 \mathrm{mmHg}$ ): 3 Bronchial segments (EHPZ mean pressure 44.67 $\mathrm{mmHg}$ ): 6 Retrocardial segments (EHPZ mean pressure $30.5 \mathrm{mmHg}$ ): 8 Aortic segments (EHPZ mean pressure $74.25 \mathrm{mmHg}$ ): AS Aortic segment: BS Bronchial segment; IBS Interbronchial segment; LES Lower esophageal sphincter: RS Retrocardial segment: X-R ND X-ray not done

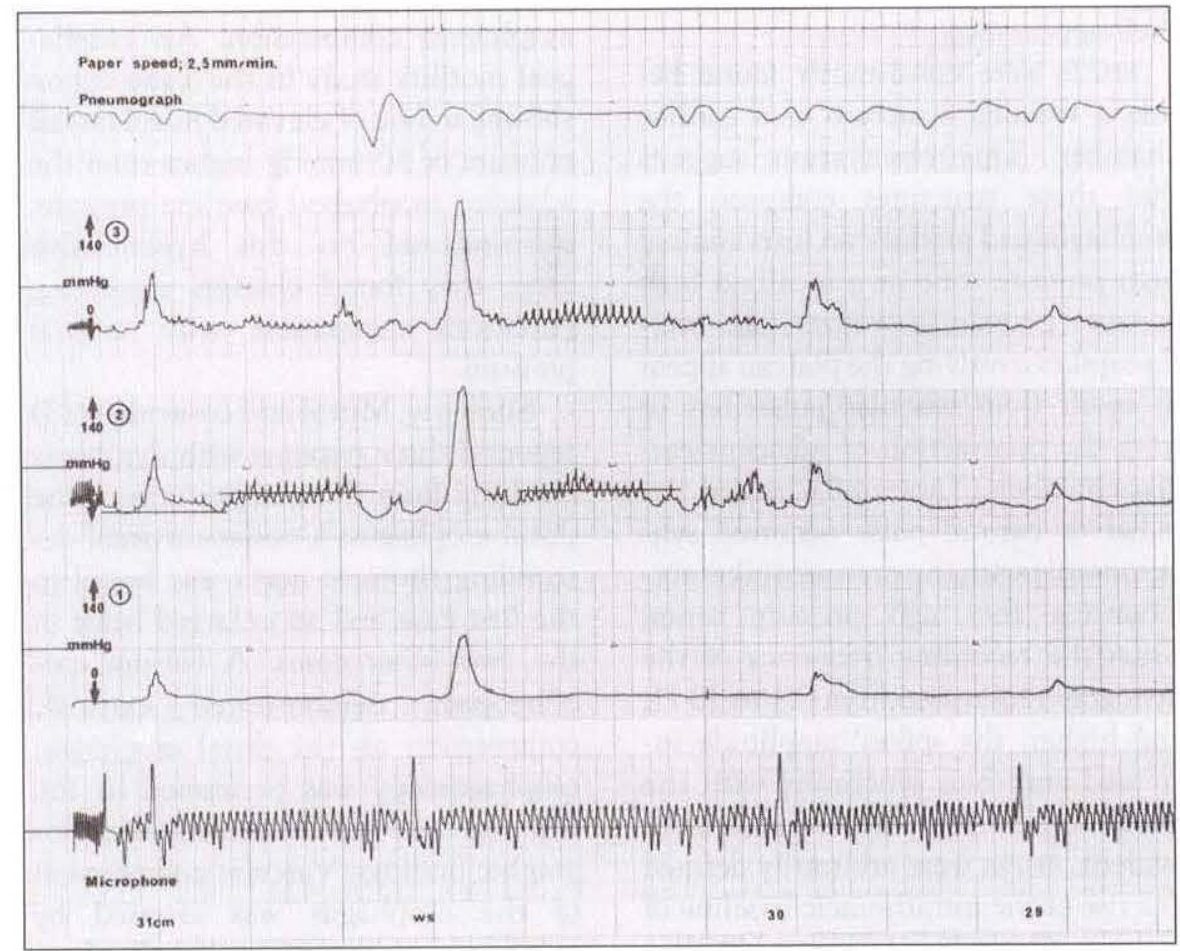

Figure 5) Effect of aorta on the esophageal wall. Esophageal manometry tracing of patient 21 recorded with the catheter's three distal side holes located at the same level and oriented at $120^{\circ}$ angles from one another. Notice the asymmetry of the esophageal high pressure zone, the pressure plateau being recorded by two of the three side holes. The miniature sound microphone is located on top of a carotid artery. The repetitive pressure spikes above the pressure plateau occur simultaneously with the carotid artery pulsations picked up by the sound microphone, which suggests that the pressure spikes are produced by the aortic pulsations on the esophageal wall 
TABLE 5

Esophageal motility studies: group 2

\begin{tabular}{ll}
\hline $\begin{array}{l}\text { Patient } \\
\text { number }\end{array}$ & Manometric findings \\
\hline 18 & Normal \\
19 & EB: $\mathrm{HCP}>180 \mathrm{mmHg}$, \\
& MWD $<5.5 \mathrm{~s}$, \\
& LES: CP $132 \mathrm{mmHg}$ \\
20 & RLESP $=44 \mathrm{mmHg}$, \\
& CLESP $=102.6 \mathrm{mmHg}$ \\
21 & Normal \\
22 & Normal
\end{tabular}

CLESP Closing lower esophageal sphincter (LES) pressure: CP Closing pressure: EB Esophageal body; HCP High contraction pressure: MWD Mean wave duration: RLESP Resting LES pressure

\section{DISCUSSION}

EHPZs have been observed by several investigators in normal volunteers as well as in conditions in which mediastinal structures significantly compress a segment of the esophagus (1-4). This study systematically evaluated their occurrence in a population presenting at a motility laboratory. Furthermore, the study aimed to determine which anatomical structures were responsible for their appearance.

EHPZs were consistently found beside a vascular structure or a cardiac chamber. This observation suggests that these structures compress the esophagus and produce an intraluminal high pressure zone or a localized high pressure plateau; moreover, the pressure spikes overlying the plateau appear to result from vascular pulsations or from the contraction of adjacent cardiac chambers (Tables 4,6). Indeed, the radial or carotid pulse occurred synchronously with the pressure spikes surmounting the high pressure zones; when the recording frequency of the dynograph increased from 0.3 to $30 \mathrm{~Hz}$ and higher, the spikes' amplitude increased and their synchrony with the radial and carotid pulse became more evident. EHPZs were arbitrarily defined as a rise of the intrathoracic baseline of at least $10 \mathrm{mmHg}$; however, we also observed instances where the high pressure zone was inferior to this predefined limit.

Berenzweig et al (2) described a case of dysphagia lusoria wherein a cine esophagogram and a barium swallow dem-

TABLE 6

Esophageal high pressure zone: group 2

\begin{tabular}{lcccc}
\hline $\begin{array}{l}\text { Patient } \\
\text { number }\end{array}$ & $\begin{array}{c}\text { Structure(s) } \\
\text { surrounding marker* }\end{array}$ & $\begin{array}{c}\text { EHPZ: } \\
\text { cm above LES }\end{array}$ & $\begin{array}{c}\text { EHPZ } \\
\text { length }(\mathrm{cm})\end{array}$ & $\begin{array}{c}\text { EHPZ pressure } \\
(\mathrm{mmHg})\end{array}$ \\
\hline 18 & AS & 10 & 1.0 & 29 \\
19 & AS & 12 & 3.0 & 16 \\
20 & RS & 7 & 1.0 & 15 \\
21 & AS & 11 & 1.0 & 22 \\
22 & AS & 14 & 1.0 & 47 \\
Total & & & 1.4 (mean) & 25.8 (mean) \\
\hline
\end{tabular}

"Manometric catheter distal radiopaque marker. AS Aortic segment: EHPZ Esophageal high pressure zone: LES Lower esophageal sphincter: RS Retrocardial segment

onstrated an external compression above the aortic arch. An esophagoscopy revealed an extraluminal defect appearing as a pulsating bandlike abnormally at $24 \mathrm{~cm}$ from the incisors. A contrast study with barium tablets and a steak meal under fluoroscopy reproduced the patient's dysphagia and confirmed that both of these meals 'hung up' at the level of the subclavian artery. An angiography demonstrated an aberrant right subclavian artery and a simultaneous barium swallow confirmed the anomalous vessel as coinciding with the site of esophageal compression. An esophageal motility study in the same region showed a zone of elevated intraluminal pressure of $10 \mathrm{mmHg}$ higher than the adjacent esophageal baseline pressure; superimposed on this hypertensive zone, they found changes suggesting pulsations compatible with arterial pressure.

Similarly, Mittal and co-workers (3) reported three patients with dysphagia resulting from the compression of the distal esophagus; a nonaneurysmal descending thoracic aorta was found in the first case and an enlarged heart in the two latter cases. A barium esophagogram demonstrated extrinsic compression on the distal esophagus; esophagoscopy was performed in the first case only and confirmed the radiographic findings. Vascular compression of the esophagus was assessed by esophageal manometry in all three cases and showed an area of increased resting intraesophageal pressure of 10 to $20 \mathrm{mmHg}$, varying in length from 3 to $5 \mathrm{~cm}$. Prominent arterial pulsations were superimposed on this part of the tracing.
Furthermore, Mittal et al (3) analyzed esophageal manometric tracings of 47 normal subjects, 39 males and eight females, mean age 31 years (range 24 to 56$)$. In 10 of these subjects they found a hypertensive zone greater than $5 \mathrm{mmHg}$ at the site of a vascular compression; they did not elaborate any further on these sites. The resting pressure ranged from 5 to $65 \mathrm{mmHg}$ and, as in this study, they noticed that the EHPZ was not circumferential (it was seen in only one lead). Again, as was shown in this study (Figures 2,3,5), the plateau pressure dropped to intraesophageal pressure prior to swallow-induced esophageal contractions, thus behaving like a sphincter. The mechanism of the pressure drop was not clear but was thought to represent movement of the recording orifice away from the compressing structure. These findings were similar to those described in the three previous patients with dysphagia. However, these investigators did not attempt to determine which mediastinal structures were producing these high pressure zones.

Recently Cappell (4) reported a case of left atrial dilation producing esophageal compression and dysphagia; using esophageal manometry and simultaneous ECG he demonstrated a localized mid-EHPZ with superimposed cyclic pressure waves and showed a one-toone correspondence between these pressure oscillations and the electrocardiographic QRS complex. He concluded that this high pressure zone represented a distinctive manometric finding in a patient with left atrial dilation, and that it resulted from mechanical compression on the esophagus. Furthermore, his study showed that su- 
perimposed cyclic pressure waves corresponded to transmitted mural pulsations.

The findings of Berenzweig, Mittal and Cappell (2-4), combined with this study's results, suggest that EHPZs reflect a compression created by the proximity of vascular or cardiac structures on the esophageal body. The work of Cappell and this study provides strong circumstantial evidence to suggest that the pressure spikes surmounting the high pressure zones correspond to systolic pulsations induced by these same structures. Mittal's observations as well as those provided in this study suggest that EHPZs may be found in normal subjects and in patients with various esophageal conditions. EHPZs do not

\section{REFERENCES}

1. Dalton CB. The manometric study. In: Castell DO, Richter JE, Dalton CB, eds. Esophageal Motility Testing. New York: Elsevier Science Publishing Co Inc, 1987:35-60.

2. Berenzweig $\mathrm{H}$, Baue AE, McCallum RW. Dysphagia lusoria. Report of a case and review of the diagnostic and necessarily have a functional significance since this manometric entity was reported more often in normal subjects than in cases where hindrance to the passage of barium or an endoscope could be demonstrated in the esophagus. To show more clearly a localized high pressure zone, one needs only to decrease the filtration frequency of the dynograph and check if the pressure spikes occur synchronously with the patient's radial pulse; otherwise, one may tape a sensitive sound recorder on a carotid artery and obtain, on the same trace, a simultaneous recording of swallows, arterial pulsations and EHPZs.

Cappell's "localized midesophageal high pressure zone" should be termed "esophageal high pressure zone". This

surgical approach. Dig Dis Sci 1980;25:630-6.

3. Mittal RK, Siskind BN, Hongo M, Flye MW, McCallum RW. Dysphagia aortica. Clinical, radiological and manometric findings. Dig Dis Sci 1986;31:379-84.

4. Cappell MS, Manometric findings in dysphagia secondary to left atrial manometric entity is due to cardiovascular phenomena and should be recognized by all those involved in performing and interpreting esophageal manometric studies. EHPZs have clinical significance only in patients where obstruction to esophageal transit can be demonstrated as in dysphagia lusoria and aortica $(2,3)$ and in patients with mitral valve disease complicated by left atrial dilation (4); it may be related, in future studies, to other pathological entities.

ACKNOWLEDGEMENTS: The authors thank Claudine and Jocelyne Poupart for assistance in preparing the manuscript and Denis Tremblay for the photographic work.

dilatation. Giant, cyclic midesophageal pressure waves occurring with every heart beat. Dig Dis Sci 1991;36:693-8.

5. Brombart M. Roentgenology of the esophagus. In: Margulis AR, Burhenne HJ, eds. Alimentary Tract Radiology, vol 1. St Louis: The CV Mosby Co, 1967:277-83. 


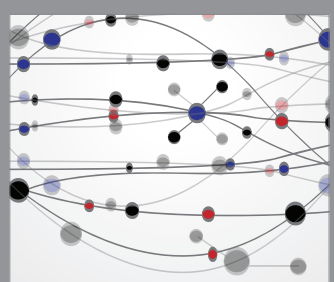

The Scientific World Journal
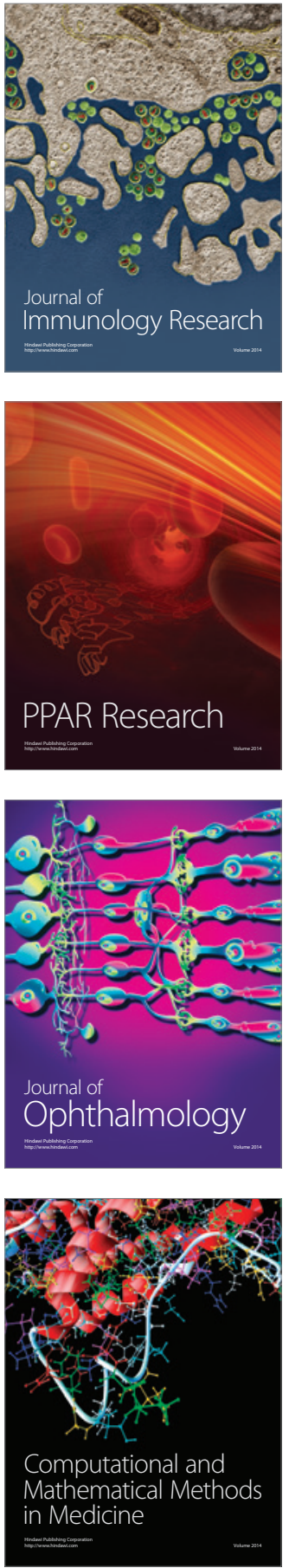

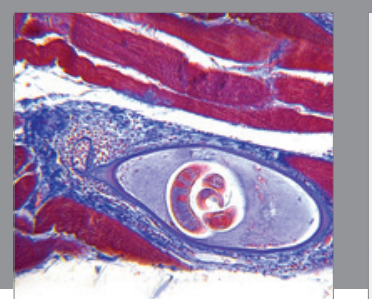

Gastroenterology Research and Practice

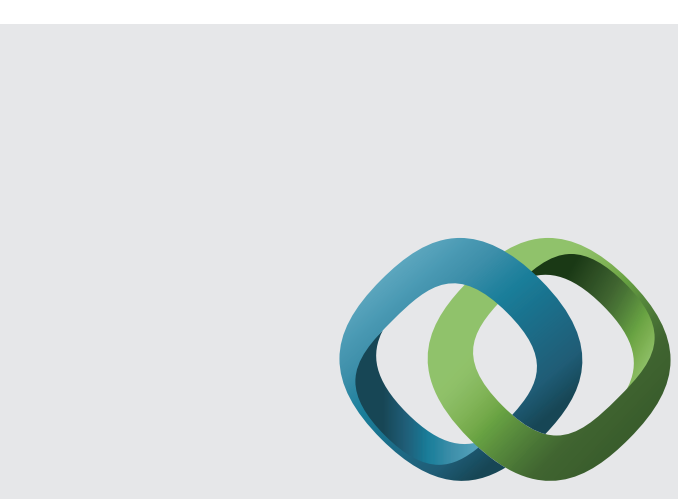

\section{Hindawi}

Submit your manuscripts at

http://www.hindawi.com
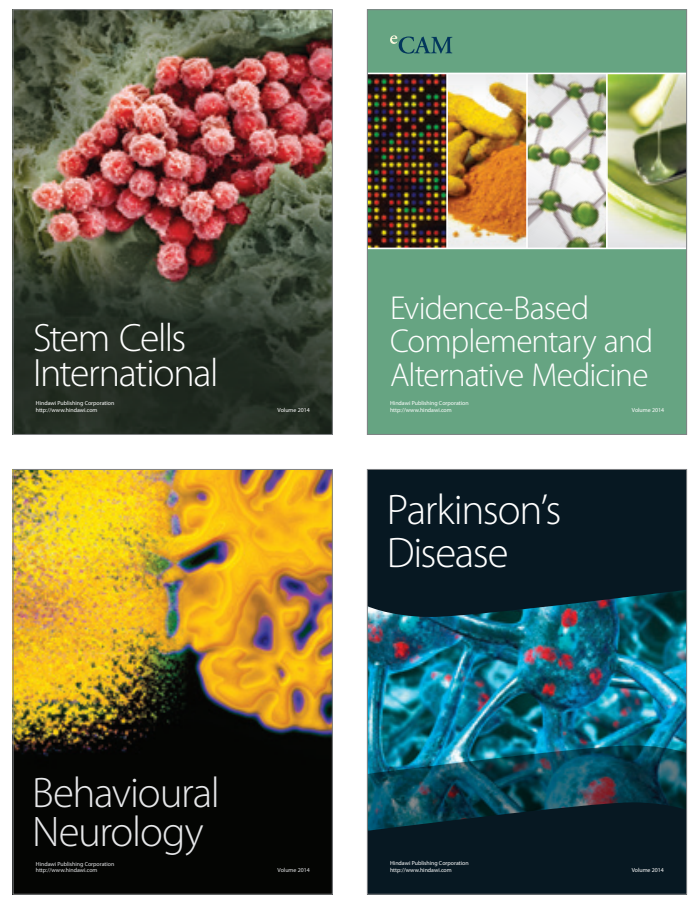
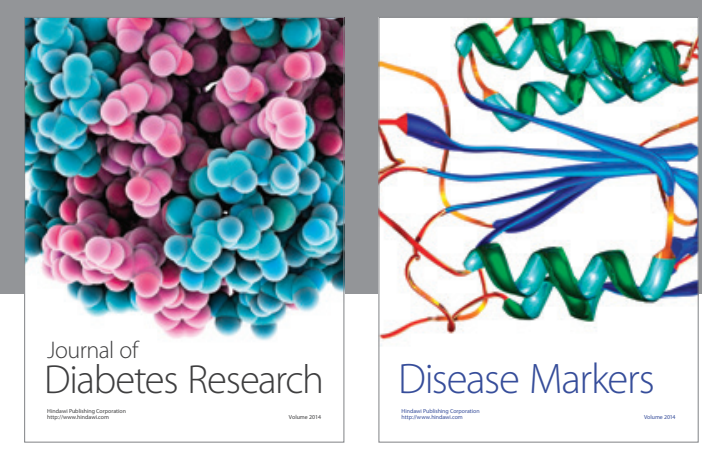

Disease Markers
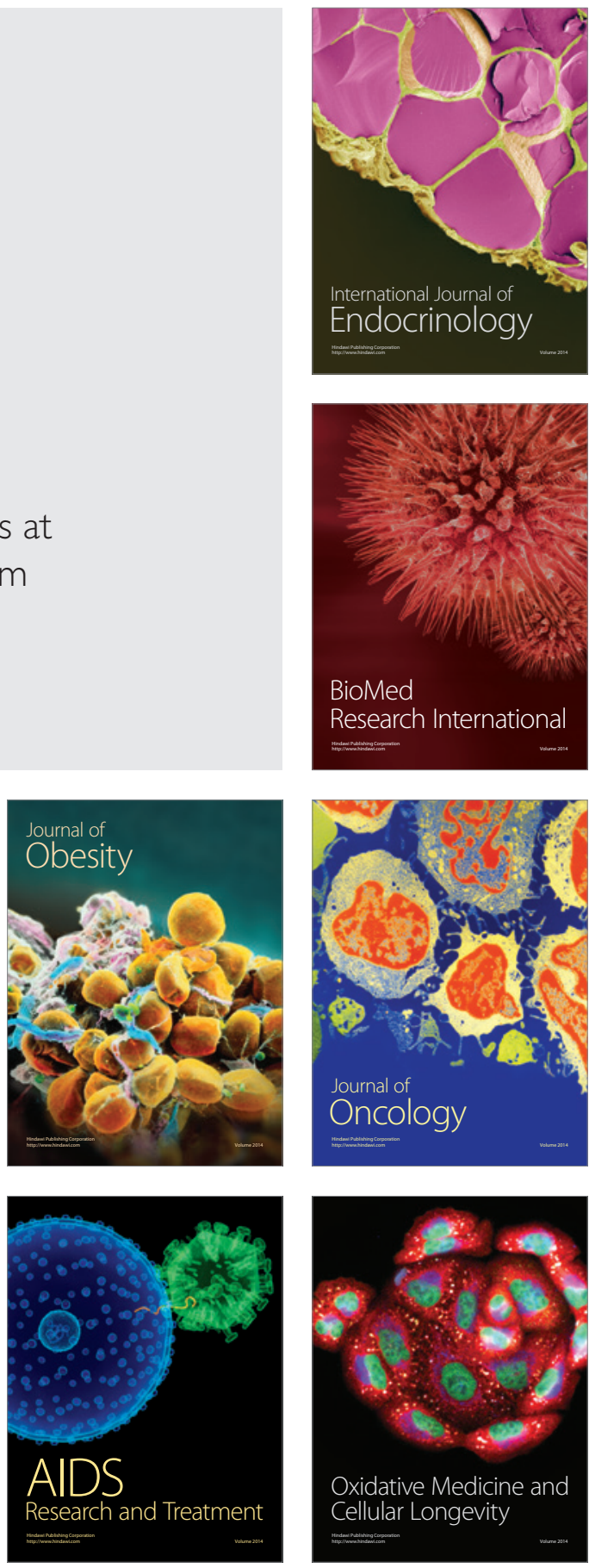